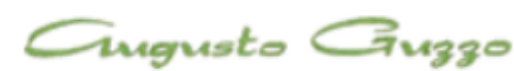

REVISTA ACADEMICA

\title{
Hakitía, apreciação duma mera narrativa
}

\author{
Álvaro Fernando Rodrigues Da Cunha',
}

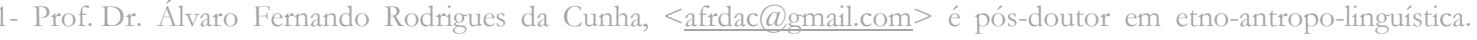
Unicamp, 2013. Doutor em Língua Portuguesa. USP, 2010. Mestre em Língua Portuguesa. USP, 2008. Graduado em Letras. Universidade da Amazônia, 2002. Domina fluentemente Inglês, espanhol, e grego. De 2012 a 2013 foi Cientista da Unicamp na criação da TeCOE® -Teoria de Cruzamento em Oralidade e Escrituralidade Unicamp. E pesquisador no Laboratório de Estudos sobre Etnicidade, Racismo e Discriminação - LEER-USP. É avaliador Ad hoc de revistas científicas Qualis brasileiras. Atual cientista em San Diego na Califórnia - Aliant International University.
\end{abstract}

1.

\section{Resumo}

A TeCOE® (Teoria de Cruzamento em Oralidade e Escrituralidade) fora desenvolvida pelo autor da pesquisa ao notar que não há na narratologia, na psicologia, na antropologia, na história, nas ciências jurídicas, na linguística nenhum tipo de recurso que auxilie àqueles que pretendem cruzar relatos orais e escritos, mas não abstraem o que está em seus âmagos, suas origens. Por vezes foram dissuadidos justamente por faltar uma técnica cujo objetivo de cruzar relatos, contos, narrativas dentre outros ainda não havia. Isso vale para a escrita e para o oral.

Vejamos, portanto, uma análise partindo do modelo supracitado, em hakitía.

\section{Tradução}

\section{Venido bueno i venido klaro!}

En Ierusalaim, viviam dos jaim. Uno deles era un felab $i$ el otro hareor. Viviam jahade, hata ke un dia bubo pelea gadol entre ejos. El hareor haldreo ke sesiñaria suio jai kando le halase. Ejillearamse $i$ kuriose el zimam. En akel entonses de la esnea lo falah obro buena koseja. El jai del felah, se apliko de pie al biade del adama ke habia, viendo las orejas de mahiz, gadol i haldreo: - Komo muestro El Dio es bueno... - Porke berakome mas ke mio jaito? - Soi esposado, tengoi famia i mia koseja fera buena. Entonses tengoi ke tener la salam kon el; ansina, hoi krusare el arojo $i$ salire a suio enlakia. Tomare mis desiplos $i$ le remitire alhadrado a ke me gustaso $i$ me indulte. El jai del felah le haldreo suios desiplos la rixom ventaja de la koseja ke tenia el hareor, $i$ haldreo a suios desiplos: - Kando mi jai los topar $i$ peskudar donde salieron $i$ adole se van, besreen ser mios desiplos $i$ kadeen haja ke remitoi ehdeo hata el. Arespondan ke salire al kamiño suio baruje-bamasil ensegida de vos. Vio el felah ke se aserko lo hareor 
kon markulah. Hubo asodeser gadol blia $i$ halhala, porke tendria fakisina. Kando el hareor regreso, bubo una dahxa i el felah enkurvose i poso suia hala en arde, señalando emuna suio jai. Ansi el hareor dio un abraso en el felah $i$ se ajoraranse jahade.

\section{Tradução}

Nem te conto! Em Jerusalém, viviam dois irmãos. Um era agricultor e o outro pastor de ovelhas. Todos moravam juntos, até certo dia haver uma briga feia entre ambos. O pastor disse que mataria a seu irmão quando o encontrasse. Separaram-se e passou-se o tempo. Na época da colheita o agricultor fez uma excelente safra. O irmão agricultor se pôs em pé ao lado das terras que tinha, olhando as altas espigas de milho e disse: - Como Deus é bom... - Por que me abençoou mais que meu irmão? - Sou casado, tenho filhos e minha colheita foi boa. - Mas preciso fazer as pazes com ele; para isso, hoje atravessarei o riacho e irei ao seu encontro. Levarei meus empregados e presentes para que se agrade de mim e me perdoe. O irmão agricultor mandou primeiro que seus servos levassem parte da colheita que fizera ao pastor de ovelhas, e disse a seus servos: - Quando meu irmão encontrar vocês e lhes perguntar de quem são e para onde vão, falem serem meus empregados e que vocês levam presentes que envio para ele. - Digam que irei ter com ele após vocês. Horas depois, viu o agricultor que se aproximava o pastor de ovelhas com alguns homens armados. Então houve grande tensão e pavor, porque haveria morte. Quando o pastor de ovelhas chegou, houve silêncio total e o agricultor inclinou-se, pôs o rosto ao chão, em sinal de respeito e bumildade a seu irmão. Então o pastor deu um abraço forte no agricultor e beijaram-se chorando juntos. 


\section{Análise Da Narrativa Pelo Plano De Cruzamento}

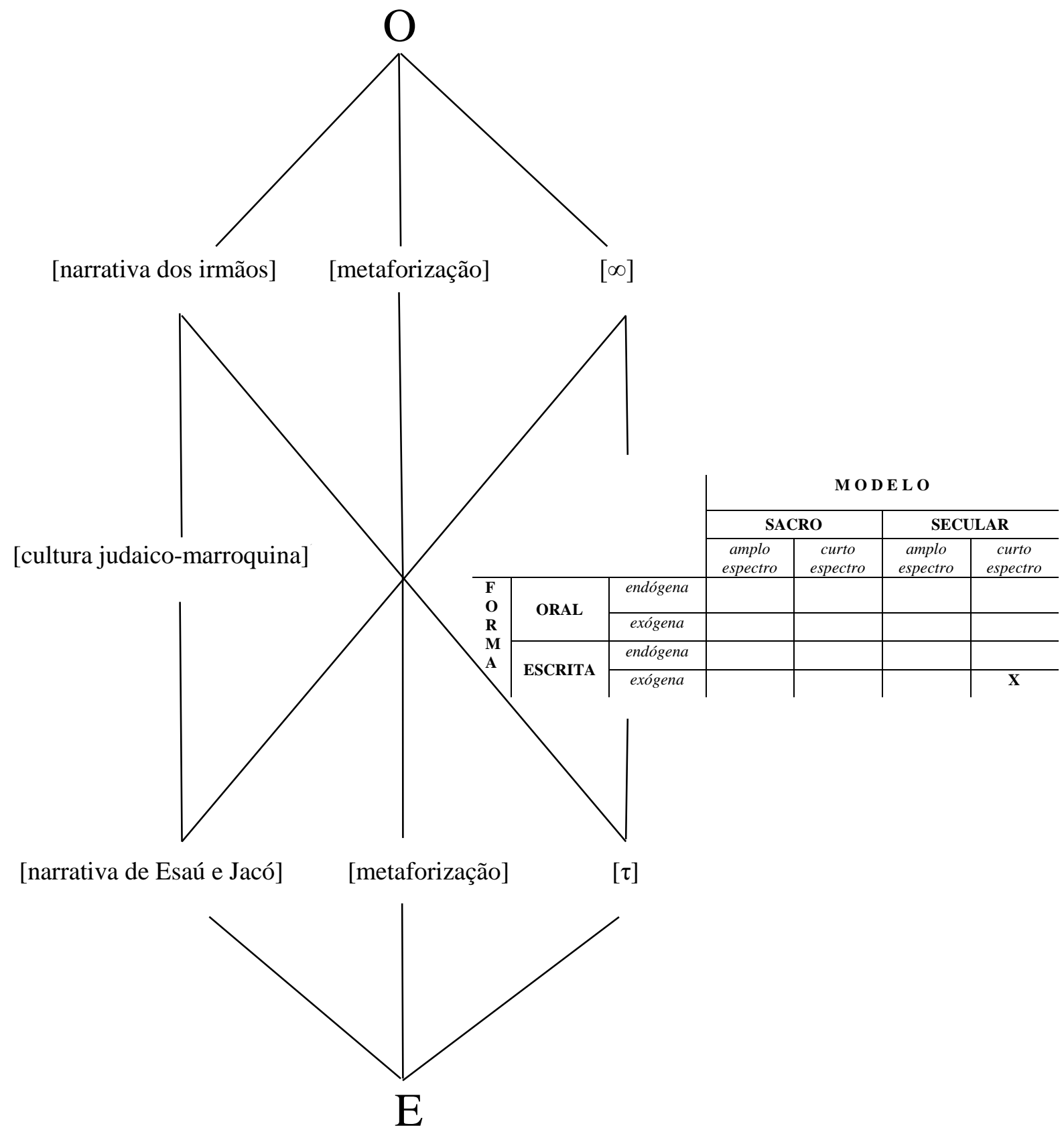

A narrativa dos irmãos está pode-se observar que a primeira ligapresa ao nó da Oralidade e a narrativa se à finitude, desde que passe à de Esaú e Jacó ao nó da categoria da Escrituralidade, ou seja, Escrituralidade. Ao cruzar a narrativa petrifica-se, congela-se, já a segunda, dos irmãos com a de Esaú e Jacó, se perder o status de Escrituralidade, 
passando a fazer parte duma cultura popular qualquer, entra na categoria da infinidade oral, pois os contadores das histórias se encarregarão de dar variadas interpretações a uma matriz que passará a ser derivada de derivadas, ou seja, ao cruzar as duas narrativas, já percebemos o primeiro Análise para início de oralidade e escrituralidade $(\alpha)$ : tripé narrativo

\section{Narrativa dos irmãos}

$(\alpha)$

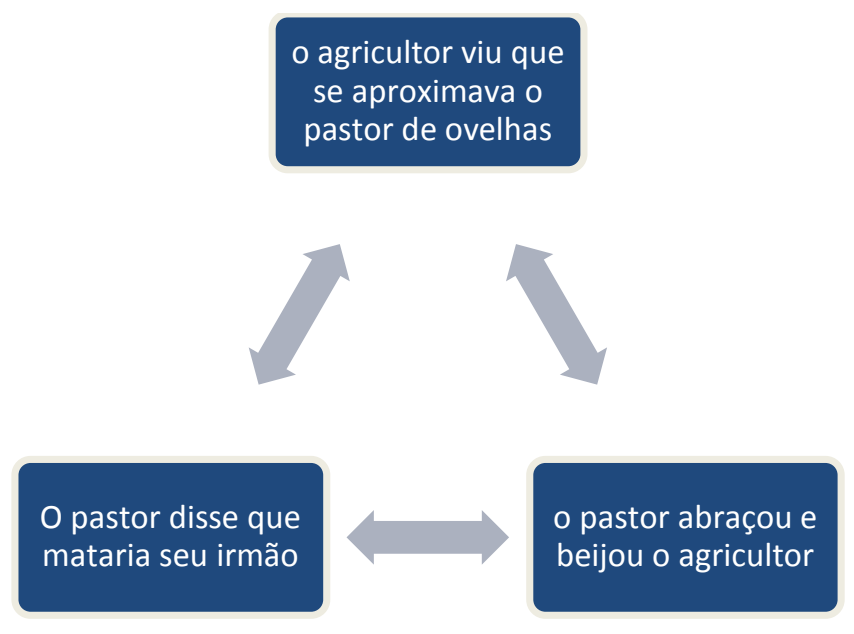

2. Narrativa de Esaú e Jacó

$(\alpha)$ 


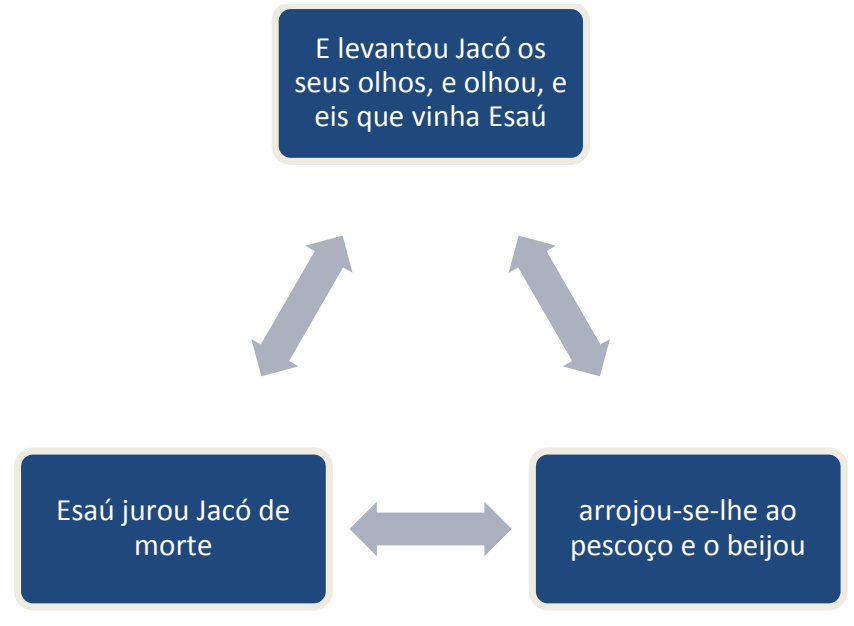

Análise para entrada e saída de metaforização na oralidade e na escrituralidade $(>\mathrm{m}<)$

1. Narrativa dos irmãos

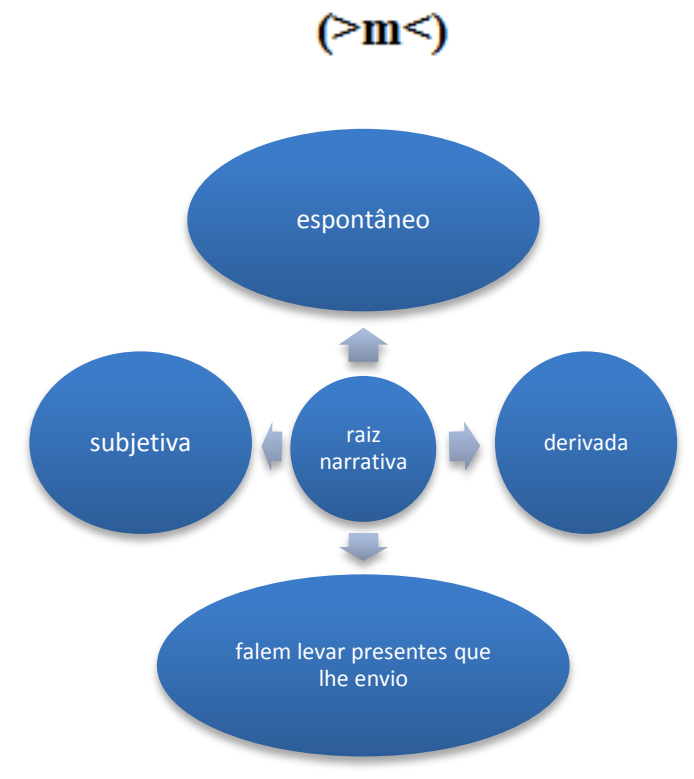

2. Narrativa de Esaú e Jacó

$(>\mathrm{m}<)$ 


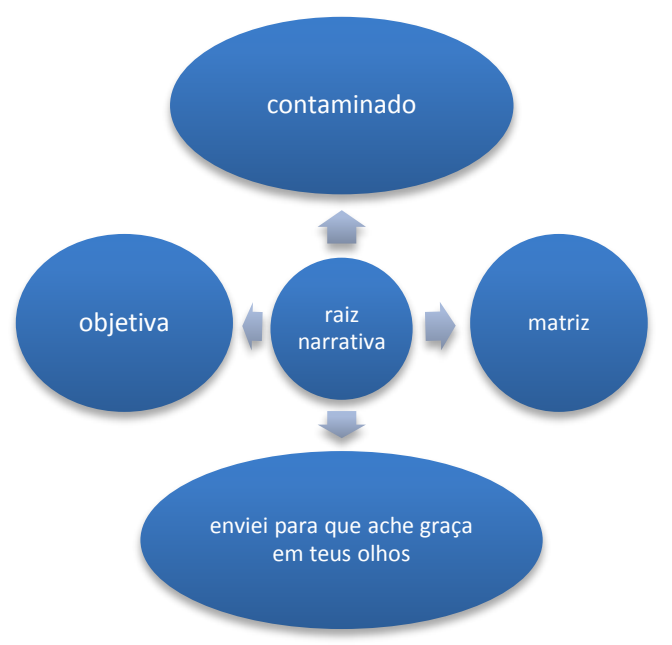

Análise para o etos $(\varepsilon)$

Antes de qualquer explicação, ressaltaremos a dispensabilidade de apreciação de dois etos, ou seja, os eventos em análise não demandam duas avaliações. Seria tautológico demais cruzar duas culturas análogas, i.e., judaísmo-marroquino sefarad com judaísmo-marroquino sefarad. Assim, não há como cruzar tais etos e ficamos com uma análise unilateral sem prejuízo do estudo em questão, uma vez que ambas narrativas são de origem sefardi.

Em hebraico, a palavra sefard que alguns também chamam sefarad, tem o significado de ocidente ou
Espanha, portanto, sefardi ou sefaradi é a denominação dada ao judeu originário do Ocidente ou da Espanha. As expressões sefardim, sefaradim ou sefardies são empregadas para indicar o ramo do judaísmo que por sua ascendência genealógica, rito, cultura e língua se relacionam com os antigos judeus da Península Ibérica. Alguns ainda os chamam de sefardi, sefardita, e sefárdico.

Sendo assim, não pode haver dúvida de que os sefardim são os descendentes dos judeus nascidos na Espanha e em Portugal, os quais iniciaram o seu êxodo do território de suas pátrias no decorrer do século XIV pela perseguição religiosa, 
culminando por sua expulsão total devido à inquisição no fim do século XV.

Os judeus sefarditas expulsos de Portugal e da Espanha mantiveram consigo e vem sendo transmitida aos seus descendentes, uma cultura peculiar, caracterizada por sua forma "babilônica" de rezar, comer, comportar-se socialmente, pensar, cantar e uma comunicação verbal privativa e até certo ponto sigilosa, perpetuada pela utilização e propagação dentro de seus lares, e que lhes era também de grande utilidade para sua identificação e segurança pessoal e comercial.

A maioria das línguas judaicas foram criadas quando os judeus tiveram acesso a normas linguísticas não-judaicas e foram familiarizados com elas. As línguas judaicas são consideradas derivadas das línguas coterritoriais cognatas, com subsequente acréscimo do superestrato hebraico-aramaico e outros componentes geolinguísticos.

Essa comunicação verbal privativa e até certo ponto sigilosa, que sempre utilizavam em seus lares e mesmo lhes servindo para identificarem-se a qual era constituída pelo dialeto "judeu-hispanomarroquino" para os que permaneceram em Marrocos ou vieram para o Brasil, e que era denominada hakitía, transportava consigo todo um esplendor cultural.

Por mais isolado que estivesse um sefardi, ele continuava praticando seus costumes, logicamente que dentro de suas possibilidades locais, porém fazendo tudo que estava ao seu alcance para no menor espaço de tempo reunir-se aos seus correligionários ou simplesmente ligar-se com eles novamente, a fim de comerem juntos a comida mais apreciada pela culinária da cultura judaico-marroquina, a adafina. Não havia maiores dificuldades quanto ao idioma: todos falavam a hakitía.

$\mathrm{O}$ moço judeu vivia "abandonado", regateando em "Éretz Amazon". Depois, formada a família, ia comerciar no interior mais afastado, comprando e vendendo mercadorias. Quando sua situação se consolidava, tratava de transferir esposa e filhos para cidades maiores, onde a criançada nascia a cada dois anos, "gerados em cada visita do pai à esposa, durante as 
páscoas e celebrações religiosas de Rosh Hashaná, Iom Kipur, Pessach, Purim, Chanuká ou para as cerimônias de Brit-Milá (circuncisão) de seus filhos, ou para o Bar Mitzvá”, (BENCHIMOL, 1998, p. 68). Esses dias festivos eram os dias de "fazer neném" com as esposas parideiras, que tinham uma média de seis a oito filhos antes de completar quarenta anos de idade.

Sem dúvida, é digno de nota, destacar a comunidade compacta que os judeus formam na Amazônia. Não se misturam, nem nos modos nem na religião. Casam-se entre primos e frequentam escolas da comunidade judaica.

À mesa judaico-marroquina, costumeira e cuidadosamente preparada, os pratos são trazidos um a um pela matriarca e por uma "afilhada" (sempre uma jovem adotada pela família para ajudar nos afazeres do lar). Lavam as mãos, sentam-se juntos e rezam a Deus dizendo "Bendicemos a ti El muestro Dio...", "Bendito sejas tu, nosso Deus...". Comem primeiramente dum prato comunitário com a mão direita, o polegar e os dois primeiros dedos.
Todas às sextas-feiras, dia conhecido como "éreve", ou seja, “véspera” do sábado, há um jantar fraterno, pois eles esperam esse momento semanal com ansiedade, por ser o dia da Aliança Espiritual com Deus. Vestem-se com as melhores roupas, adornam-se e perfumam-se. As crianças tomam banho pelas $16 \mathrm{~h} \mathrm{e}$ toda a família começa o ritual litúrgico por volta das $18 \mathrm{~h}$.

As matriarcas já deixam toda a refeição preparada como outros pormenores na sexta mesmo. Aos "shabatot", "sábados", a família vai reunida à "snoga", "sinagoga" contente e feliz encontrar-se com a noiva chamada sábado, enfim, ter chegado. Não acendem fogo nem lavam a louça após a refeição, porque é proibida qualquer espécie de trabalho nesse dia santo para eles. Esse comportamento tem base no quarto mandamento da lei divina (ler na Bíblia Êxodo 20) que diz: "Lembra-te do Dia de Sábado [...] neste dia não trabalharás [...]". O dia é de louvores e orações voltados a Deus. Nada é assunto mais importante que a bondade e misericórdia divinas. 
As moças aguardam pelo casamento virgens. Os rapazes, sempre muito respeitadores com tudo e com todos, seguem à risca os modos ensinados pelos pais cuja regra de conduta baseia-se na Torá.

A família é em geral numerosa, pois além do pai e da mãe há quatro, cinco, seis filhos, além da afilhada.

Como hoje em dia os estudos são indispensáveis os pais geralmente orientam os filhos a cursarem medicina, direito ou magistério. A explicação se deve em razão de essas três profissões serem imprescindíveis à sociedade e de relevância, pois em havendo necessidade de eles servirem aos próximos, os que trabalham com a saúde agem para reparar o enfermo, os que laboram com a justiça conhecem a lei para defenderem os injustiçados e os que lidam com o magistério formam opiniões e criam teorias para a sociedade crescer. São esforçados ao limite e dão o melhor de si no que fazem. Traduzindo, são profissões estratégicas e de destaque, até porque se houver uma nova onda de perseguição, dificilmente esses profissionais e suas famílias serão perseguidos, pois gozam do respeito e admiração dos companheiros de labor e da sociedade como um todo.

É quase impossível haver um litígio entre esses elementos e o restante da sociedade, haja vista evitarem qualquer exposição que reflita direta ou indiretamente na comunidade e ficarem rotulados; ao contrário, quando a situação ganha desdobramentos a orientação é deixarem a causa e se evadirem, justamente para evitar contendas. Geralmente são mansos e humildes no trato alheio; conformados e nada egoístas, esse perfil é típico e peculiar desse povo. Salvaguardando as óbvias e devidas exceções.

São descontraídos, alegres e por vezes até inocentes, pois enxergam o mundo sob uma ótica ingênua. Levam tudo com candura, mesmo porque assim foram criados, isto é, como não fazem mal a ninguém acreditam que toda a sociedade proceda do mesmo modo.

Não comem fora do lar por regra religiosa, ou seja, alimentos "puros e impuros" (ler na Bíblia Levítico 11). Só o fazem se houver extrema necessidade e mesmo assim 
só comem o que está permitido na Torá.

$\mathrm{Na}$ educação a criança aprende ler por volta dos três ou quatro anos de idade. Não abriremos discussão sobre aquisição de leitura na infância, mas geralmente entre eles isso constitui regra. É orgulho para a família ver o filho a ler a Torá em hebraico.

Quando o menino completa treze anos, atinge a maioridade religiosa e para marcar este rito de passagem, celebra-se o famoso "Bar Mitzváh", "Filho do Mandamento" para os homens, ou seja, é nesse momento que pela primeira vez o menino é convidado a ler a Torá em público. Já o "Bat Mitzváh", "Filha do Mandamento" para meninas que completam doze anos, marca a transição da fase infantil para a adulta e o tempo que elas assumem seus compromissos com a religião e a comunidade. É um ritual significativo respondendo a um convite da tradição e da fé, em geral seguido por uma festa oferecida pela família aos parentes e amigos.
A vida social é indissociável da vida religiosa, mas é digno de nota que há judeus que não vão à sinagoga, porém cumprem com os mandamentos por mais paradoxal que seja, pois um dos mandamentos é ir à sinagoga. A Aliança é com Deus e não com os homens. O compromisso é com Deus e não com a sinagoga.

Quando solteiros, não se misturam com pessoas que não fazem parte da comunidade, geralmente se mudam de cidade, estado ou até de país a fim de casarem. Curioso é que não importa a cultura do outro, pois o que se leva em consideração é o fator de fé judaica. É bom lembrar que não basta apenas dizer que é judeu, tem de se provar burocraticamente, de fato e de direito, ser judeu. Só o testemunho oral é frívolo e considerado insano pelos rabinos, o que diverge da opinião das autoridades jurídicas em Israel que dizem ser judeu todo e qualquer ser humano que pratique a religião e os costumes do povo israelita.

Os grupos de amizades são formados no seio da sinagoga; há aqui e ali um ou outro caso de judeus que levam amigos não-judeus para dentro 
de seus lares, mas isso não constitui regra geral.

As narrativas são diferentes das demais, pois o que mais se encontram são relatos que sempre têm como fim algo que esteja escrito na Torá. Seja direta ou indiretamente como visto. A criação é bastante rígida, pois os pais exigem muito dos filhos, já que a qualquer momento pode haver outra caça aos judeus. Isso talvez se deva ao fato de séculos de hostilidade contra o tipo israelita.

Como supracitado, casamento "só entre os parentes", há aqueles que se unem aos não-judeus, mas são raríssimos. Mesmo nos dias atuais, esses ainda sofrem com a discriminação e a intolerância, pois a família judaica tem como objetivo final o culto racional ao Deus de Israel. Assim, os hebraicos da Amazônia são, na medida do possível, homogêneos, o que nos permite afirmar que os judeus-marroquinos ainda estão presos fortemente às raízes seja do lar judaizante aos negócios seculares.

\section{Análise para a forma $(\mu)$}

Forma oral endógena e modelo secular de curto espectro, conforme proposta do autor da pesquisa, pois essa narrativa é conhecida só na comunidade judaico-marroquina que fala a hakitía e forma escrita exógena e modelo sacro de amplo espectro, pois o relato bíblico de Esaú e Jacó é conhecido no universo judaico-cristão.

\begin{tabular}{|c|c|c|c|c|c|c|}
\hline & \multicolumn{4}{|c|}{ MODELO } \\
\hline & & & \multicolumn{2}{|c|}{ SACRO } & \multicolumn{2}{|c|}{ SECULAR } \\
\hline & & & $\begin{array}{l}\text { amplo } \\
\text { espectro }\end{array}$ & $\begin{array}{c}\text { curto } \\
\text { espectro }\end{array}$ & $\begin{array}{l}\text { amplo } \\
\text { espectro }\end{array}$ & $\begin{array}{l}\text { curto } \\
\text { espectro }\end{array}$ \\
\hline $\mathbf{F}$ & \multirow{2}{*}{ ORAL } & endógena & & & & \\
\hline $\mathbf{O}$ & & exógena & & & & \\
\hline $\mathbf{R}$ & \multirow{2}{*}{ ESCRITA } & endógena & & & & \\
\hline $\mathbf{M}$ & & exógena & & & & $\mathbf{X}$ \\
\hline
\end{tabular}




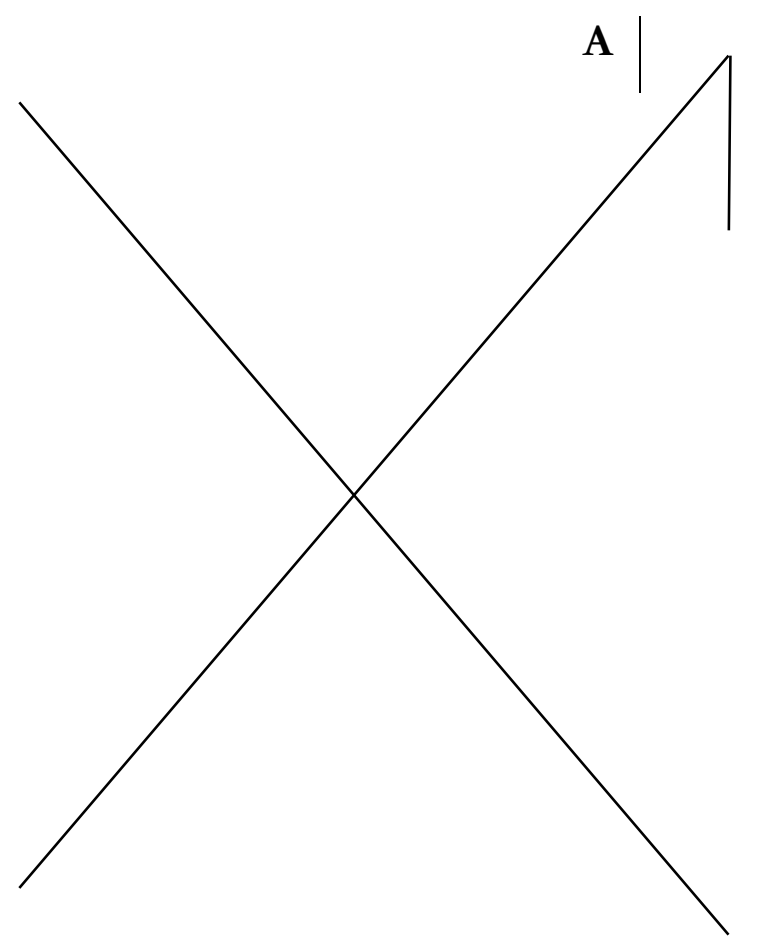

Indubitavelmente quando entramos no terreno da oralidade estamos no âmago da alma humana, de sua cultura, de sua tradição, de sua língua(gem), onde encontramos abundante outros relatos largamente distribuídos, porém de modo inteiramente caracterizado, reconstruindo-se, convertendo-se. Segundo afirmou-se supra, há uma razão especial sobre por que são preferidas. É justificável indagar: estas três relações, espaço, tempo, forma se criaram no mundo todo? Caso afirmativo, pode-se dizer que, temos, de fato, características basilares do pensamento humano. A descrença e o ceticismo devem rondar abundantemente o espírito do investigador. São essas narrativas universais ou se desenvolveram historicamente com o passar do tempo, da forma, do espaço? E se essas narrativas não são universais, mas dispersas não historicamente, há então um determinismo psicológico sob certas condições dadas?

Não podemos ainda caracterizar a fortiori o que se passa nas culturas mundo afora, mas podemos a priori cruzar relatos e estabelecermos critérios para a oralidade. Pois é por ela que nos interessamos, i.e., o primeiro escopo da oralidade abordado neste trabalho, ou seja, a oralidade pura sem submissão à escrita; aquela oralidade 
permanente na memória e transmitida pela voz, apriorística sem a intervenção da oralidade nas sociedades letradas, ou mesmo aquela que não está submissa à escrituralidade posta em contraste com a realização oral da língua, ou seja, aquela que está atrelada às propriedades mais gerais do ser, apartada da infinidade de determinações que, ao qualificá-lo particularmente, ocultam sua natureza plena e integral; a oralidade não afetada, não contaminada pela simbiose do tradicionalismo escrituralístico e literário.

Espero ter contribuído para o exame das narrativas em hakitía e ter trazido algum progresso para o campo de estudo na Tradição Oral, onde ficou explícito que, através das análises, o judeu-marroquino é uma língua singular e plena de semelhanças — nos seus contos - com o Velho Testamento bíblico.

Shalom vibrante desde a Amazônia!

\section{Referências}

CUNHA, A. Teoria de cruzamento em oralidade e escrituralidade. São Paulo: Miami, 2012.

GEERTZ, C. A interpretação das culturas. Rio de Janeiro: Zahar, 1989.

GOODY, J.; WATT, I. As consequências do letramento. São Paulo: Paulistana, 2006.

LE GOFF, J. História e memória. Campinas: Unicamp, 1990.

LINTON, R. O homem: uma introdução à antropologia. São Paulo: Martins, 1971.

MALINOWSKI, B. Magia, ciência e religião. Lisboa: 70, 1984.

ONG, W. Oralidade e cultura escrita. Campinas: Papirus, 1998.

PETERSON, E. A mensagem: Bíblia em linguagem contemporânea. São Paulo: Vida, 2011. 